\title{
Joint Stiffness
}

National Cancer Institute

\section{Source}

National Cancer Institute. Joint Stiffness. NCI Thesaurus. Code C79603.

A sensation of discomfort and tightness while moving a joint. Typically there is decreased joint range of motion. Causes include arthritis, joint overuse, joint injury, and the aging process. 